\title{
Grain refinement of cast peritectic TiAl-based alloy by solid-state phase transformations
}

\author{
K. Kamyshnykova ${ }^{1,2 *}$, J. Lapin ${ }^{1}$ \\ ${ }^{1}$ Institute of Materials and Machine Mechanics, Slovak Academy of Sciences, \\ Dúbravská cesta 9, 84513 Bratislava, Slovak Republic \\ ${ }^{2}$ Slovak University of Technology in Bratislava, Paulínska 16, 91724 Trnava, Slovak Republic
}

Received 2 May 2018, received in revised form 21 September 2018, accepted 1 October 2018

\begin{abstract}
The effect of solid-state phase transformations on grain refinement of cast peritectic TiAl-based alloy with nominal composition Ti-47Al-5Nb-0.2B-0.2C (at.\%) has been investigated. Three multi-stage heat treatment routes consisting of pretreatment in single $\alpha$ phase field followed by air, oil or water cooling and subsequent annealing in $\alpha+\gamma$ or single $\alpha$ fields were applied to refine grain structure of the alloy. The microstructure of the as-cast samples consists of coarse fully lamellar $\alpha_{2}\left(\mathrm{Ti}_{3} \mathrm{Al}\right)+\gamma(\mathrm{TiAl})$ grains with a grain size of $1310 \mu \mathrm{m}$. The annealing of the pretreated samples consisting of massive $\gamma_{\mathrm{M}}$ and fine lamellar $\alpha_{2}+\gamma$ grains in the $\alpha+\gamma$ phase field leads to the formation of a duplex type of microstructure composed of lamellar $\alpha_{2}+\gamma$ and single $\gamma$ phase grains with a grain size ranging from 14 to $22 \mu \mathrm{m}$. The solution annealing in the single $\alpha$ phase field of the pretreated samples aged in the $\alpha+\gamma$ phase field leads to the formation of fully lamellar $\alpha_{2}+\gamma$ grains with a grain size ranging from 395 to $472 \mu \mathrm{m}$.
\end{abstract}

K e y words: titanium aluminides, TiAl, heat treatment, grain refinement, phase transformation, microstructure

\section{Introduction}

Intermetallic TiAl-based alloys are promising structural materials for high-temperature aerospace and automotive industry applications up to about $750{ }^{\circ} \mathrm{C}[1-6]$. Depending on their chemical composition and processing parameters, these alloys can be produced with four different types of microstructure: near-gamma (NG), duplex (DP), near lamellar (NL) and fully lamellar (FL). The DP/NG alloys are characterised by higher room temperature (RT) tensile strength, ductility and longer fatigue life than FL/NL ones [7]. On the other hand, the FL/NL alloys exhibit better creep resistance, higher fracture toughness and crack propagation resistance than DP/NG structures $[8,9]$. However, a coarse-grained lamellar structure results in low RT tensile strength and ductility $[7,10]$. The yield strength and ductility of TiAl-based alloys can be significantly increased by decreasing grain size [11]. On the other hand, Parthasarathy et al. [12] and
Maruyama et al. [13] have reported that the grain size ranging from 70 to $1200 \mu \mathrm{m}$ has negligible or no effect on creep behaviour of FL alloys. Kim and Kim [14] have shown that a good balance between RT mechanical properties and high temperature creep resistance can be achieved by an appropriate heat treatment leading to a fully lamellar equiaxed grain structure with a grain size of about $280 \mu \mathrm{m}$.

Basically, two main approaches have been investigated to refine the coarse-grained structure of ascast TiAl-based alloys: (i) solid-state phase transformations and (ii) alloying with minor additions. Numerous research works have been published on grain refinement based on solid-state phase transformations and particularly on non-equilibrium phase transformations [15-23]. Indeed, a large range of microstructures can be obtained by varying the cooling rate from the $\alpha$ (Ti-based solid solution with A3 crystal structure) phase field ranging from the equilibrium lamellar structure to the Widmanstätten structure, feath-

*Corresponding author: e-mail address: kateryna.kamyshnykova@savba.sk 
Table 1. The chemical composition of as-cast samples (at.\%)

\begin{tabular}{cccccccc}
\hline $\mathrm{Ti}$ & $\mathrm{Al}$ & $\mathrm{Nb}$ & $\mathrm{B}$ & $\mathrm{C}$ & $\mathrm{O}$ & $\mathrm{H}$ & $\mathrm{N}$ \\
\hline $47.6 \pm 0.3$ & $46.5 \pm 0.4$ & $5.3 \pm 0.2$ & $0.22 \pm 0.02$ & $0.22 \pm 0.02$ & $0.14 \pm 0.02$ & $0.010 \pm 0.003$ & $0.010 \pm 0.003$ \\
\hline
\end{tabular}

ery structure, massive structure and finally the highly metastable retained $\alpha$ structure. The massive structure has been used as a precursor for subsequent heat treatments because it leads to a refined and isotropic structure [24-26]. The massive transformation is the diffusionless transformation of the $\alpha$ phase to massive $\gamma_{\mathrm{M}}(\mathrm{TiAl})$ which strongly depends on $\mathrm{Al}$ content and is significantly influenced also by alloying additions. The alloying elements showing low diffusivity in both $\mathrm{TiAl}$ and $\mathrm{Ti}_{3} \mathrm{Al}$ phases decrease critical cooling rates required for the formation of massive $\gamma_{M}$ [19]. Some TiAl-based alloys have been specifically designed, as the "air hardenable" requiring only air cooling from the single $\alpha$ phase field to be fully transformed to massive $\gamma_{M}[10,27-31]$. However, many TiAl-based alloys do not exhibit massive transformation or this transformation is shifted to very high cooling rates. Therefore, alternative heat treatment processes based on solid-state phase transformations of the retained $\alpha$ have been developed to refine the coarse-grained structure and optimise their mechanical properties [32].

$\mathrm{Hu}$ et al. [33, 34] have reported that low boron additions are very effective to refine the grain structure of TiAl-based alloys. Recently Kamyshnykova and Lapin [35] have shown that low addition of boron was ineffective to refine coarse-grained structure hypoperitectic and peritectic TiAl-based alloys prepared by vacuum induction melting in graphite crucibles and casting into graphite moulds. Since the coarse lamellar grain structure reduces RT ductility and tensile strength significantly, additional processing routes based on solid-state phase transformations need to be developed to refine the grain structure of such peritectic type of TiAl-based alloys.

This study aims to evaluate the effect of solid-state phase transformations on grain refinement of cast peritectic TiAl-based alloy with a nominal composition Ti-47Al-5Nb-0.2B-0.2C (at.\%). In this alloy, niobium is added to improve oxidation resistance, creep strength and tensile strength [36]. Minor additions of boron and carbon were added to influence grain structure formation and improve creep resistance, respectively $[37-39]$.

\section{Experimental procedure}

Table 1 shows the measured chemical composition of the studied alloy. The as-cast bar was machined to smaller samples with a diameter of $17 \mathrm{~mm}$ and length of $26 \mathrm{~mm}$ using wire electrical discharge machining.

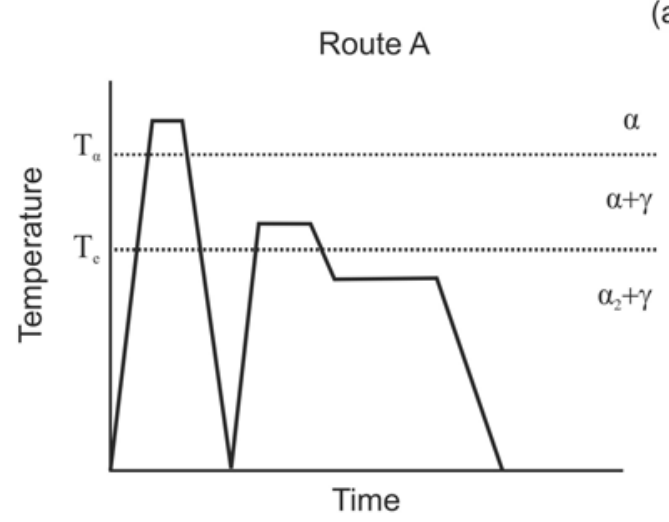

(a)

(b)

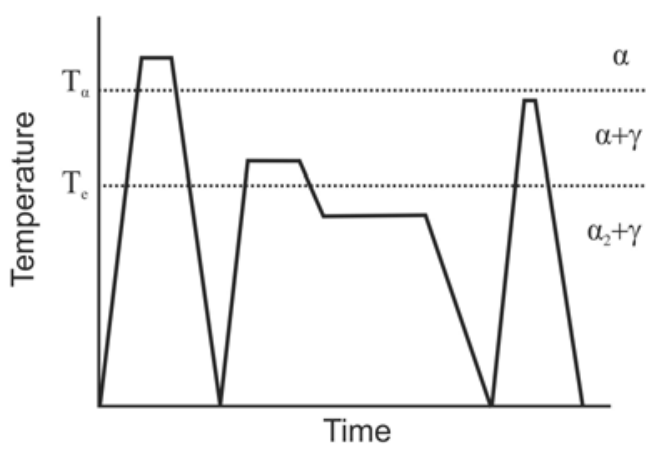

Route C

(c)

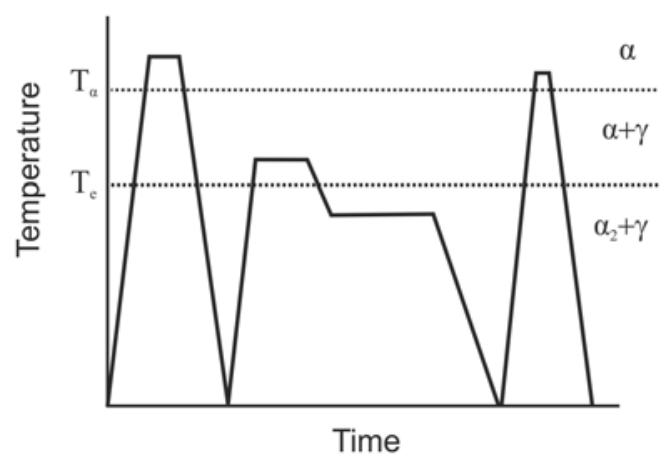

Fig. 1. Schematic views of heat treatment routes applied in the present study: (a) heat treatment route A; (b) heat treatment route $\mathrm{B}$; (c) heat treatment route C. $T_{\alpha}$ is $\alpha$ phase transition temperature; $T_{\mathrm{e}}$ is eutectoid temperature.

The samples were heated to a solution annealing temperature of $1405^{\circ} \mathrm{C}$ at a heating rate of $10^{\circ} \mathrm{C} \mathrm{min}{ }^{-1}$, held at this temperature for $1 \mathrm{~h}$ and cooled to room temperature using forced air cooling, oil quenching 


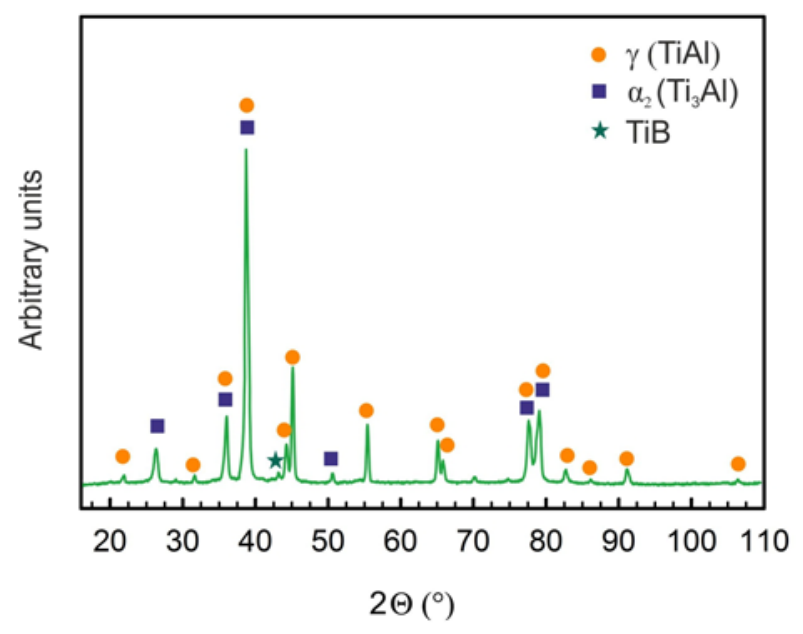

Fig. 2. The typical XRD pattern of the as-cast samples.

and water quenching which resulted in average cooling rates of 15,24 and $48{ }^{\circ} \mathrm{C} \mathrm{s}^{-1}$, respectively [31]. The air cooled (AC), oil quenched (OQ) and water quenched (WQ) samples were subjected to three different heat treatment routes designated as $\mathrm{A}, \mathrm{B}$, and $\mathrm{C}$, as seen in Fig. 1. The heat treatment route $A$ consisted of the heating of the pretreated AC, OQ and WQ samples to an annealing temperature of $1225^{\circ} \mathrm{C}$ at a heating rate of $10^{\circ} \mathrm{C} \mathrm{min}{ }^{-1}$, holding in $\alpha+\gamma$ phase field at $1225^{\circ} \mathrm{C}$ for $4 \mathrm{~h}$, cooling to a temperature of $900{ }^{\circ} \mathrm{C}$ at a cooling rate of $10^{\circ} \mathrm{C} \mathrm{min}{ }^{-1}$, holding in $\alpha_{2}+\gamma$ phase field at $900^{\circ} \mathrm{C}$ for $20 \mathrm{~h}$ and furnace cooling to room temperature, as shown in Fig. 1a. The heat treatment route $\mathrm{B}$ included the route $\mathrm{A}$ which was followed by the heating of the samples to a temperature of $1360^{\circ} \mathrm{C}$ at a heating rate of $10^{\circ} \mathrm{C} \mathrm{min}{ }^{-1}$, holding in $\alpha+\gamma$ phase field at $1360^{\circ} \mathrm{C}$ for $0.5 \mathrm{~h}$, cooling to a temperature of $700^{\circ} \mathrm{C}$ at a cooling rate of $10^{\circ} \mathrm{C}$ and furnace cooling to room temperature, as shown in Fig. 1b. The heat treatment route $\mathrm{C}$ included the route $\mathrm{A}$ which was followed by the heating of the samples to a temperature of $1385^{\circ} \mathrm{C}$ at a heating rate of $10^{\circ} \mathrm{C} \mathrm{min}{ }^{-1}$, holding in single $\alpha$ phase field at $1385^{\circ} \mathrm{C}$ for $0.5 \mathrm{~h}$, cooling to a temperature of $700^{\circ} \mathrm{C}$ at a cooling rate of $10^{\circ} \mathrm{C} \mathrm{min}-1$ and furnace cooling to room temperature, as shown in Fig. 1c.

The heat treatments were carried out in a resistance furnace under an argon atmosphere. The temperature of the samples was measured by PtRh10-Pt thermocouple touching the specimen surface.

Metallographic preparation of the samples consisted of conventional grinding using abrasive papers, polishing on diamond pastes with various grain size up to $1 \mu \mathrm{m}$ and etching in a solution of $100 \mathrm{ml} \mathrm{H}_{2} \mathrm{O}$, $6 \mathrm{ml} \mathrm{HNO}_{3}$ and $3 \mathrm{ml} \mathrm{HF}$. Microstructure evaluation was performed by light microscopy (LM), scanning electron microscopy (SEM) and scanning electron microscopy in back-scattered electron (BSE) mode. Oxy-
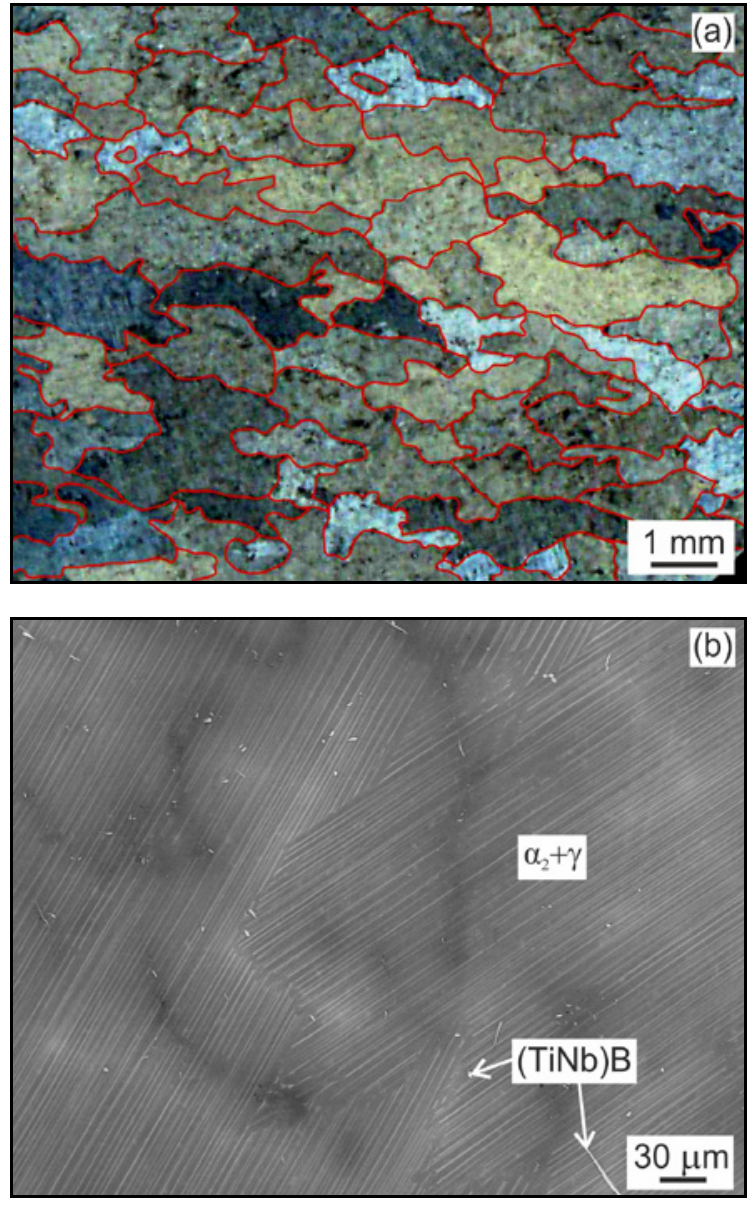

Fig. 3. Macrostructure and microstructure of the as-cast samples: (a) coarse equiaxed and elongated grains, LM; (b) a fully lamellar microstructure with numerous borides, BSE.

gen, hydrogen and nitrogen contents were measured by LECO ONH836, and carbon content was determined by LECO CS844 elemental analysers. The chemical composition of the samples was evaluated by energydispersive spectroscopy (EDS). The X-ray diffraction (XRD) analysis of coexisting phases was carried out by a diffractometer Bruker D8 equipped with X-ray tube with rotating $\mathrm{Cu}$ anode operating at $12 \mathrm{~kW}$. Volume fraction of phases was measured by computerised image analysis using digitalised micrographs. The grain size was measured by a linear intercept method, and the measured data were treated statistically.

\section{Results and discussion}

\subsection{Microstructure and grain size of as-cast samples}

Figure 2 shows the typical XRD pattern of the Ti-46.5Al-5.3Nb-0.22B-0.22C (at.\%) samples indicating the presence of three consisting phases: $\gamma(\mathrm{TiAl})$, 

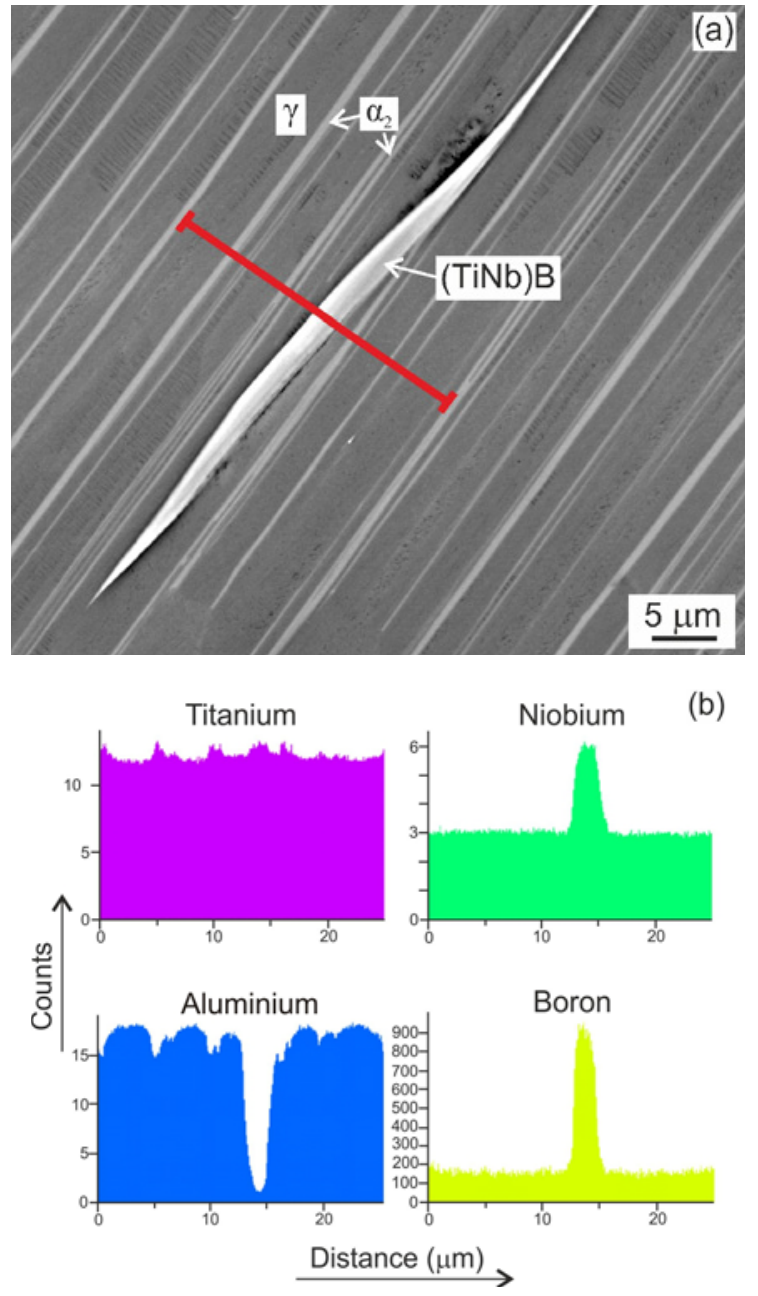

Fig. 4. (a) BSE micrograph showing the position of the line EDS analysis through the boride particle and wellaligned $\alpha_{2}$ and $\gamma$ lamellae; (b) distribution of titanium, aluminium, niobium and boron along the analysed line shown in Fig. 3a.

$\alpha_{2}\left(\mathrm{Ti}_{3} \mathrm{Al}\right)$ and $\mathrm{TiB}$. The macrostructure and microstructure of the as-cast samples are shown in Fig. 3. The coarse equiaxed and elongated grains consist of well-aligned lamellae and numerous boride particles, as seen in Figs. 3a,b. Figure 4 shows the detail of the lamellar $\alpha_{2}+\gamma$ microstructure with the position of the line EDS analysis. The line EDS analysis indicates positions of the $\gamma$ lamellae characterised by an increased aluminium content, $\alpha_{2}$ lamellae by an increased content of titanium and boride particle by an increased content of boron and niobium, as shown in Figs. 4a,b. The average chemical composition of the boride particles measured by EDS is Ti-10Nb$56 \mathrm{~B}$ (at.\%) and corresponds to $\mathrm{Ti}: \mathrm{Nb}$ ratio of $3.4: 1$. Therefore, the most appropriate formula for the boride particle can be expressed as $(\mathrm{Ti}, \mathrm{Nb}) \mathrm{B}$ that reflects the complex monoboride compound formation during solidification. However, the measured composition of the

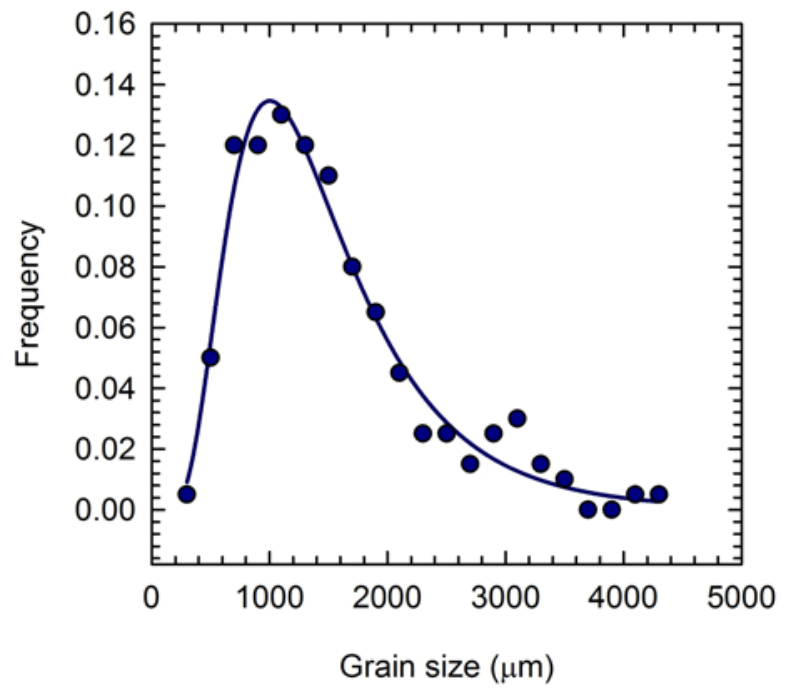

Fig. 5. The log-normal distribution function of initial grain size of the as-cast samples.

boride particles is only indicative due to the fundamental restriction regarding the low sensitivity of the EDS analysis to the determination of light elements including boron. Cheng [40] has reported that the $\mathrm{Ti}: \mathrm{Nb}$ ratio in the boride particles alloys corresponds to $3: 1$ in Ti-8Nb- $x \mathrm{~B}$ (at.\%) alloys. Kartavykh et al. [41] have reported different $\mathrm{Ti}: \mathrm{Nb}$ ratio corresponding to $1: 1$ in the boride particles formed in directionally solidified Ti-44Al-7Nb-2B (at.\%) alloy measured by calibrated Auger spectroscopy. Figures $3 \mathrm{a}$ and $3 \mathrm{~b}$ clearly indicate that the alloying with boron is ineffective to refine the coarse-grained structure of the studied alloy. Hecht et al. [37] have reported that the grain refinement with low boron additions fails when the peritectic reaction is a part of the solidification path because the peritectic $\alpha$ grains formed during growth from the liquid invade the microstructure through the subsequent solid-state transformations. The statistical analysis of the measured grain size (about 500 measurements) can be fitted by a log-normal distribution function characterised by a median value of (1310 $\pm 30) \mu \mathrm{m}$, as shown in Fig. 5. The correlation coefficient of this fit is $r^{2}=0.97$. Such large grain size leads to a very low RT tensile strength and ductility of the studied alloy and needs to be refined by appropriate heat treatments.

\subsection{Effect of continuous cooling from $\alpha$ phase field on the microstructure}

Figure 6 shows the microstructure of the samples after the pretreatment consisting of solution annealing in the single $\alpha$ phase field at $1405^{\circ} \mathrm{C}$ for $1 \mathrm{~h}$ followed by the air cooling, oil quenching and water quenching. The cooling rate of $15^{\circ} \mathrm{C} \mathrm{min}-1$ in the $\mathrm{AC}$ sample 

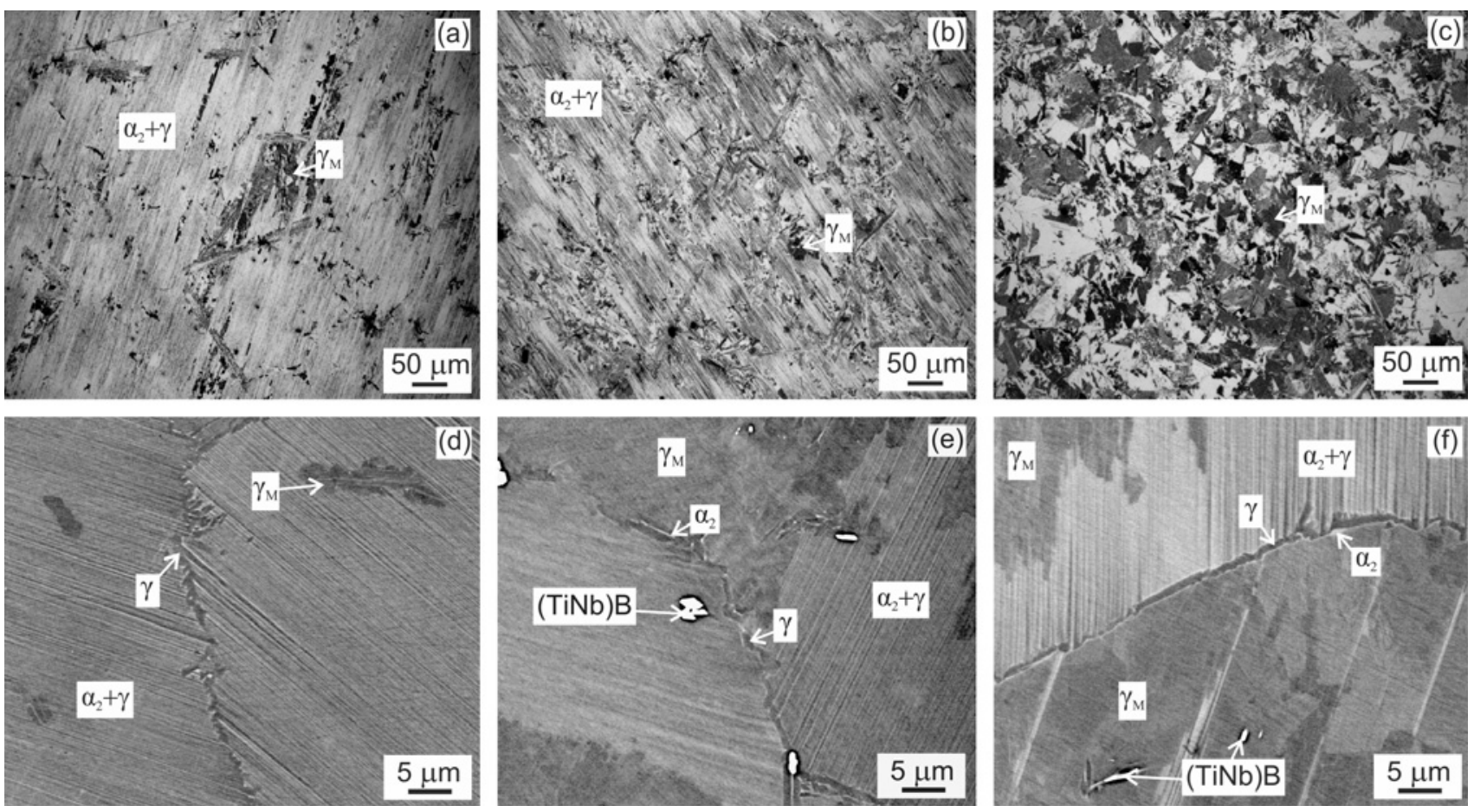

Fig. 6. Microstructures after cooling from solution annealing temperature of $1405^{\circ} \mathrm{C}$ using air cooling, oil quenching and water quenching: (a) AC sample, LM; (b) OQ sample, LM; (c) WQ sample, LM; (d) BSE micrograph showing grain boundary of AC sample; (e) BSE micrograph showing grain boundary of OQ sample; (f) BSE micrograph showing grain boundary of WQ sample.

results in the transformation of the $\alpha$ phase to fine lamellar $\alpha_{2}+\gamma$ microstructure with the low volume fraction of the massive $\gamma_{\mathrm{M}}(7 \mathrm{vol} . \%)$ forming predominantly intragranularly, as illustrated in Figs. 6a,d. The higher cooling rate of $24^{\circ} \mathrm{C} \mathrm{s}^{-1}$ in the OQ sample leads to the formation of lamellar $\alpha_{2}+\gamma$ microstructure with a higher volume fraction of the massive $\gamma_{\mathrm{M}}$ (33 vol.\%) compared to that of the AC sample, as seen in Fig. 6b. Although the massive $\gamma_{\mathrm{M}}$ is still nucleated preferentially intragranularly, its nucleation activity at the grain boundaries increases, as seen in Fig. 6e. Further increase of the cooling rate to $48^{\circ} \mathrm{C} \mathrm{s}^{-1}$ in the WQ sample leads to an increase of volume fraction of the massive $\gamma_{\mathrm{M}}$ to 48 vol. $\%$ and transformation of the remaining $\alpha$ phase to fine lamellar microstructure, as seen in Figs. 6c and 6f. In this case, the massive $\gamma_{M}$ is formed intragranularly as well as along some grain boundaries (Fig. 6f).

The main controlling factors affecting the massive transformation in TiAl-based alloys are initial microstructure, chemical composition, cooling rate, solution annealing temperature and time. Although intragranular nucleation of massive $\gamma_{\mathrm{M}}$ has been reported during continuous cooling from $\alpha$ phase field [26], it is generally accepted that the nucleation occurs predominantly at $\alpha / \alpha$ grain boundaries $[42,43]$. The $\gamma_{\mathrm{M}}$ nuclei generally exhibit a Blackburn orientation relationship with one of the adjacent $\alpha$ grains while they grow at the expense of the other grain by the movement of highly mobile incoherent interfaces. The $\gamma_{\mathrm{M}}$ domains contain a high density of lattice defects such as dislocations, stacking faults, fine twins, and antiphase boundaries. The present study indicates that the intragranular nucleation of the massive $\gamma_{\mathrm{M}}$ occurs preferentially in the $\mathrm{AC}$ and $\mathrm{OQ}$ samples. The majority of the grain boundaries contain single $\gamma$ phase which clearly reduces the nucleation activity of the massive $\gamma_{M}$, as shown in Figs. 6d,e. The nucleation of the massive $\gamma_{\mathrm{M}}$ at the grain boundaries is more frequent in the WQ samples. In this case, the grain boundary $\gamma$ is still preserved but it is separated by a thin layer of the $\alpha$ phase at which the $\gamma_{M}$ nucleates and then propagates within the grain. However, the adjacent $\alpha$ grain transforms to fine fully lamellar $\alpha_{2}+\gamma$ microstructure, as seen in Fig. 6f. The formation of the grain boundary $\gamma$ has also been reported by Huang et al. [17] in Ti-46Al-8Nb (at.\%) alloy cooled from the $\alpha$ phase field at a nominal cooling rate of $40^{\circ} \mathrm{C} \mathrm{s}^{-1}$. The formation of lamellar microstructure in the WQ sample indicates that the cooling rate of $48^{\circ} \mathrm{Cs}^{-1}$ is still too low to suppress diffusion assisted transformation of the $\alpha$ phase to the lamellar structure and to promote formation of higher volume fraction of the massive $\gamma_{\mathrm{M}}$ or to preserve untransformed $\alpha$ phase in the microstructure similarly to that observed by several authors [28, 31]. 

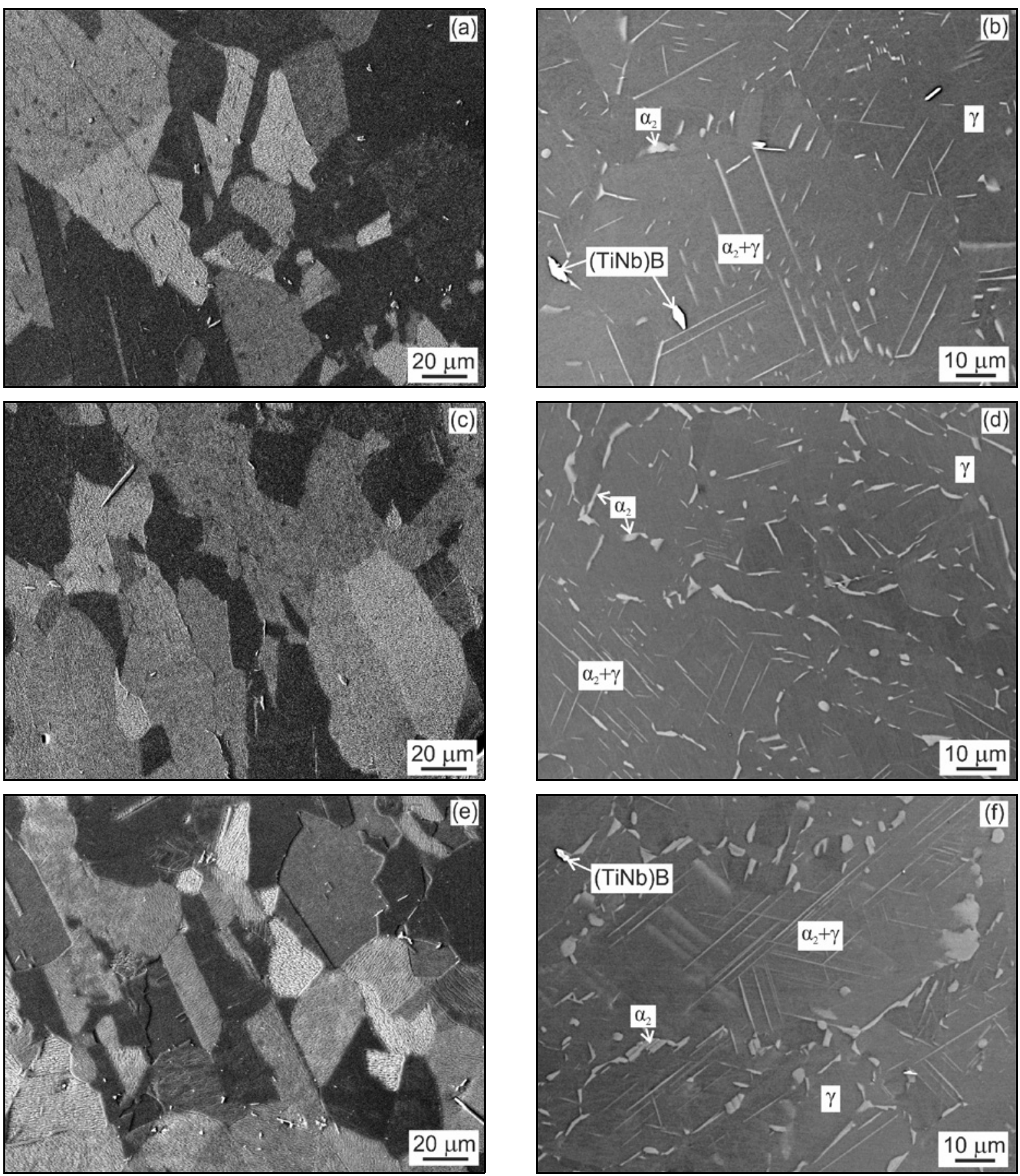

Fig. 7. Microstructure of the $\mathrm{AC}, \mathrm{OQ}$ and $\mathrm{WQ}$ samples after the heat treatment route A: (a) grain structure of the AC sample, SEM; (b) convoluted microstructure of the AC sample, BSE; (c) grain structure of the OQ sample, SEM; (d) convoluted microstructure of the OQ sample, BSE; (e) grain structure of the OQ sample, SEM; (f) convoluted microstructure of the WQ sample, BSE.

\subsection{Effect of heat treatment routes on microstructure and grain size}

\subsubsection{Heat treatment route A}

Figure 7 shows the microstructure of the AC, OQ and WQ samples subjected to the heat treatment route A. The annealing temperature of $1225^{\circ} \mathrm{C}$ cor- responds to the $\alpha+\gamma$ phase field of the studied alloy and leads to the formation of a high volume fraction of the $\gamma$ phase. The stabilisation annealing in $\alpha_{2}+\gamma$ phase field at $900^{\circ} \mathrm{C}$ leads to the growth of secondary $\alpha_{2}$ lamellae in the $\gamma$ matrix. After the annealing, the microstructure of the samples consists of refined grains with well-defined grain boundaries, as shown in Figs. 7a,c,e. Two types of microstructures can be 


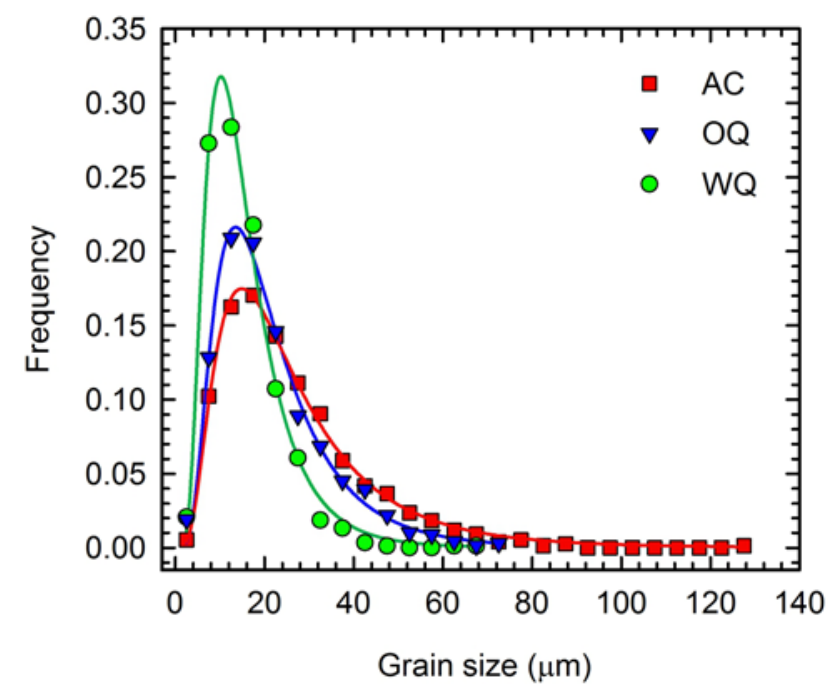

Fig. 8. Log-normal grain size distribution of the AC, OQ and WQ samples after the heat treatment route A.

identified within the refined grains such as single $\gamma$ phase and two-phase $\alpha_{2}+\gamma$, as shown in Figs. 7b,d,f. The $\alpha_{2}+\gamma$ grains contain either low volume fraction of partially dissolved aligned or fine crossed $\alpha_{2}$ lamellae. The grain boundaries of both types of grains are covered by coarsened $\alpha_{2}$ phase. The statistical analysis of the measured grain size of the AC, OQ and WQ samples (about 800 measurements for each sample) leads to log-normal distribution functions, as shown in Fig. 8. The correlation coefficients of these fits are better than $r^{2}=0.98$. The distribution curves indicate that a higher volume fraction of the massive $\gamma_{\mathrm{M}}$ leads to a more homogeneous distribution of the grain size in the annealed samples. While the grains with a size of about $120 \mu \mathrm{m}$ are preserved in the microstructure of the $\mathrm{AC}$ samples, the maximum measured grain size is only about $70 \mu \mathrm{m}$ in the WQ sample. Figure 9 shows the dependence of median grain size on the applied heat treatment route. The decrease of the grain size from 22.4 to $13.7 \mu \mathrm{m}$ in the samples subjected to the heat treatment route $\mathrm{A}$ can be related to an increase of the volume fraction of the massive $\gamma_{\mathrm{M}}$ from 7 to 48 vol. $\%$.

Two main mechanisms are responsible for the grain refinement during annealing at $1225^{\circ} \mathrm{C}$. The first mechanism is the formation of the refined grains with the convoluted type of microstructure during the transformation of the unstable massive $\gamma_{\mathrm{M}}$ by the precipitation of the $\alpha$ plates with four crystallographic variants on $\{111\}$ crystallographic planes of the $\gamma$ phase with tetragonal crystal structure $\mathrm{L}_{0}$, as shown in Fig. 7f [28]. The second mechanism responsible for the grain refinement is the discontinuous coarsening leading to the formation of lamellar grains with coarse lamellar microstructure and single $\gamma$ phase grains due

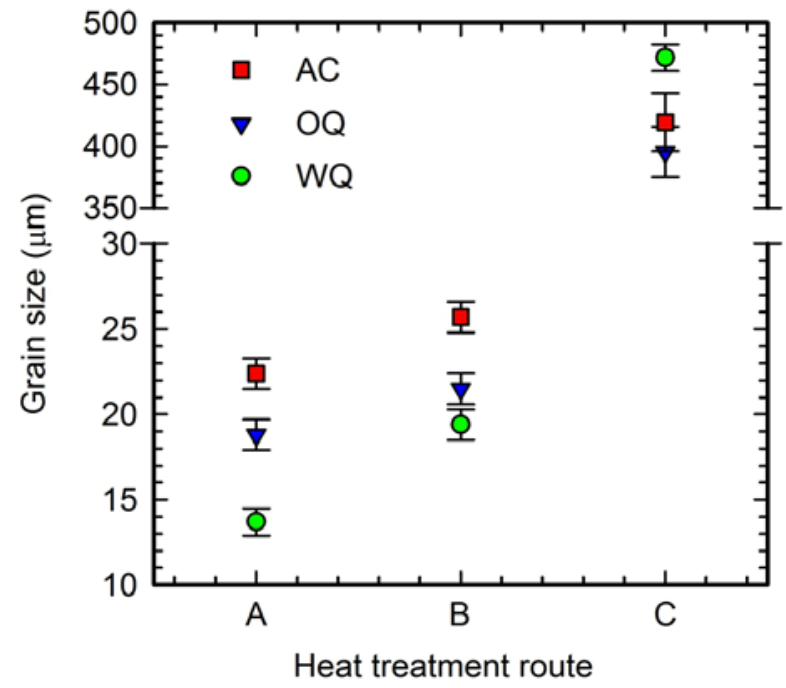

Fig. 9. Dependence of grain size of the AC, OQ and WQ samples on the applied heat treatment routes $\mathrm{A}, \mathrm{B}$ and $\mathrm{C}$.

to highly stable interfaces of the primary fine lamellar microstructure $[44,45]$. The discontinuous reaction occurs at the grain boundaries and within the original fine lamellar colonies of the AC, OQ and WQ samples. The driving force for the discontinuous coarsening is a reduction of $\alpha / \gamma$ interface energy by increasing interlamellar spacing, change of chemical composition and volume fraction of coexisting phases to attain phase equilibrium [44].

\subsubsection{Heat treatment route $B$}

Figure 10 shows microstructure of the AC, OQ and WQ samples subjected to the heat treatment route B. The selected annealing temperature of $1360{ }^{\circ} \mathrm{C}$ corresponds to the $\alpha+\gamma$ phase field of the studied alloy and leads to the formation of a high volume fraction of the $\alpha$ phase. The duplex type of microstructure of the AC, OQ and WQ samples consists of refined grains with two types of a microstructure such as single $\gamma$ phase and lamellar $\alpha_{2}+\gamma$, as shown in Figs. 10ac. The grain boundaries contain coarsened $\alpha_{2}$ particles. The duplex type of microstructure formed during the heat treatment route $\mathrm{B}$ is very similar to that of $\mathrm{Ti}-47 \mathrm{Al}-2 \mathrm{Nb}-2 \mathrm{Cr}$ (at.\%) alloy reported recently by Thomas and Bacos [46]. The statistical analysis of the measured grain size of the $\mathrm{AC}, \mathrm{OQ}$ and $\mathrm{WQ}$ samples (about 800 measurements for each sample) leads to log-normal distribution functions, as shown in Fig. 11. The correlation coefficients of these fit are better than $r^{2}=0.98$. The distribution curves indicate that the volume fraction of the massive $\gamma_{M}$ has no significant effect on the distribution of the measured grain size after the heat treatment route $\mathrm{B}$. The median grain size ranging from 16.0 to $18.4 \mu \mathrm{m}$ indicates that this 

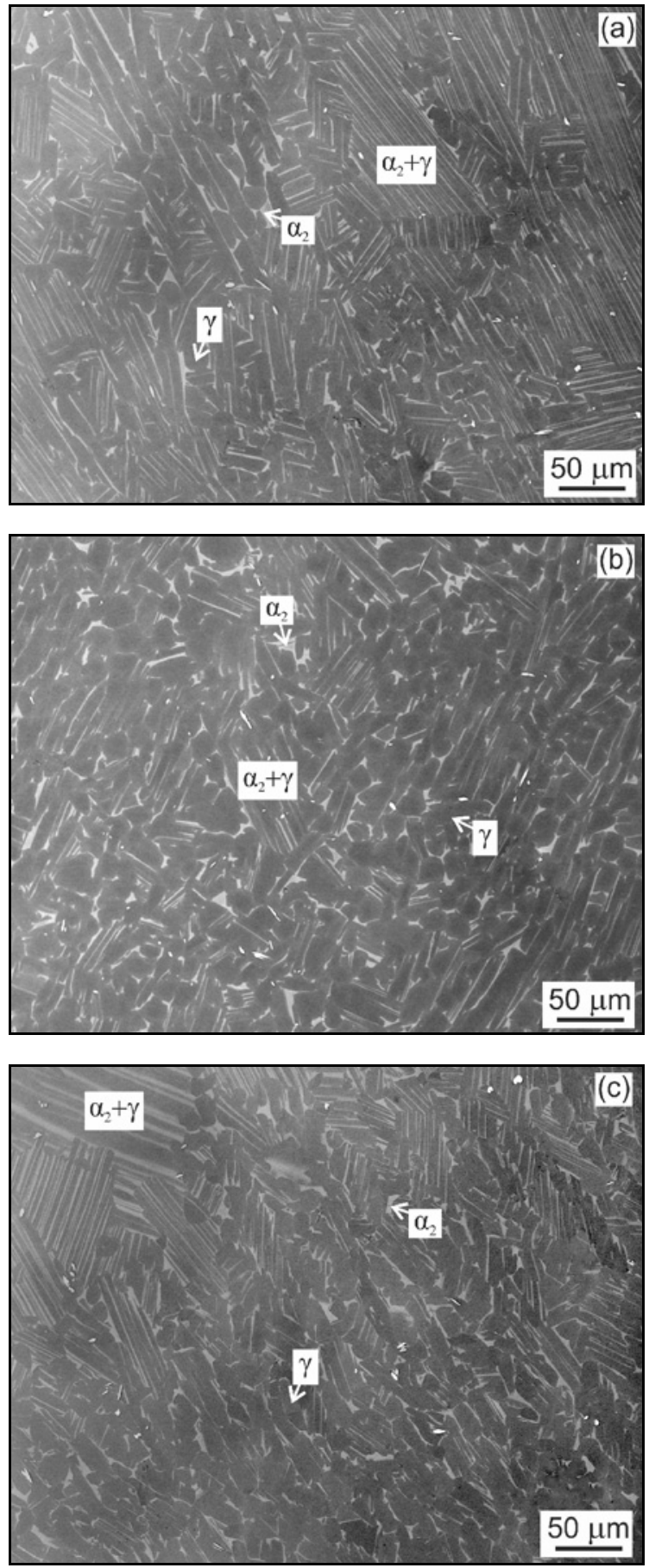

Fig. 10. BSE micrographs showing duplex microstructure after the heat treatment route $\mathrm{B}$ : (a) AC sample; (b) OQ sample; (c) WQ sample.

additional annealing step in the $\alpha+\gamma$ phase field at $1360^{\circ} \mathrm{C}$ has a negligible effect on the grain size compared to that of the samples subjected to the heat treatment route $\mathrm{A}$.

\subsubsection{Heat treatment route $C$}

Figure 12 shows the microstructure of the AC,

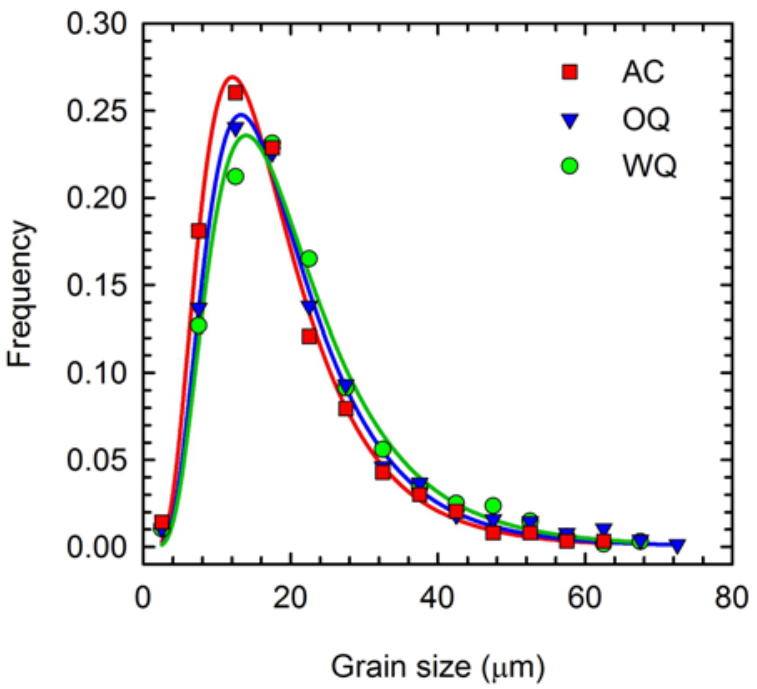

Fig. 11. Log-normal grain size distribution of the AC, OQ and WQ samples after the heat treatment route.

OQ and WQ samples subjected to the heat treatment route $\mathrm{C}$. The selected annealing temperature of $1385^{\circ} \mathrm{C}$ corresponds to the single $\alpha$ phase field of the studied alloy. The microstructure of the samples consists of coarse lamellar $\alpha_{2}+\gamma$ grains, as shown in Figs. 12a-c. Formation of the fully lamellar microstructure results from the precipitation of $\gamma$ lamellae in either the disordered $\alpha$ or ordered $\alpha_{2}$ matrix [47]. During the continuous cooling from the single $\alpha$ phase field the formation of the $\gamma$ lamellae starts in the $\alpha+\gamma$ phase field and is finalised in the $\alpha_{2}+\gamma$ phase field. The whole sequence of the lamellar structure formation involves change of the crystal structure from hcp to fcc by propagation of Shockley partial dislocations in the $\alpha$ matrix, chemical composition change by atom transfer by a combined shear and diffusion process and ordering reaction of fcc structure leading to the final tetragonal $\mathrm{L}_{0}$ structure of the $\gamma$ phase [47]. The statistical analysis of the measured grain size of the AC, OQ and WQ samples leads to log-normal distribution functions, as seen in Fig. 13. The correlation coefficients of these fits are better than $r^{2}=0.97$. The distribution curves indicate that the grain growth is faster in the WQ sample exhibiting a narrow grain size distribution after the heat treatment route $\mathrm{A}$. The median grain size of $472 \mu \mathrm{m}$ measured in the WQ sample is higher than those of 419 and $395 \mu \mathrm{m}$ of the $\mathrm{AC}$ and OQ samples, respectively. The main mechanism affecting the grain structure of the AC, OQ and WQ samples during annealing in the $\alpha$ phase field is the growth of the $\alpha$ grains which can be described by an equation in the form [48]:

$$
d=k t^{n} \exp \left(-\frac{Q}{R T}\right)
$$



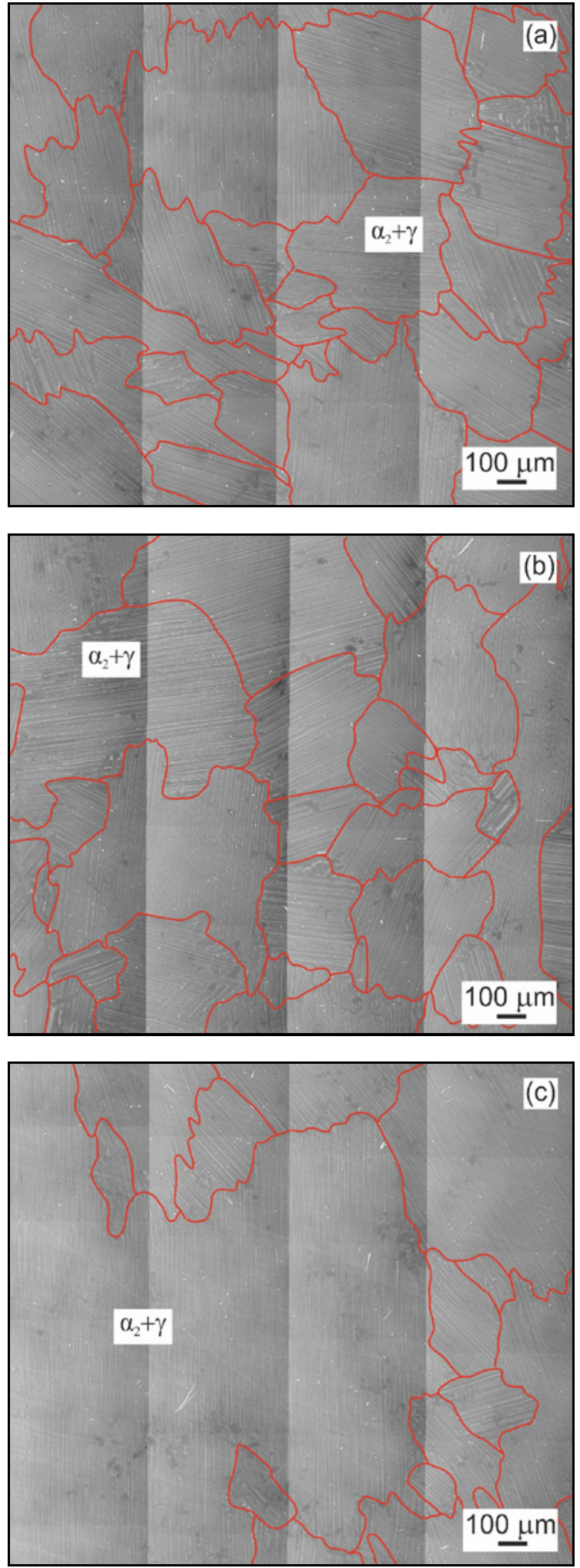

Fig. 12. BSE micrographs showing fully lamellar microstructure after the heat treatment route $\mathrm{C}$ : (a) AC sample; (b) OQ sample; (c) WQ sample.

where $d$ is the grain size, $k$ is the material constant, $t$ is the annealing time, $n$ is the time exponent, $Q$

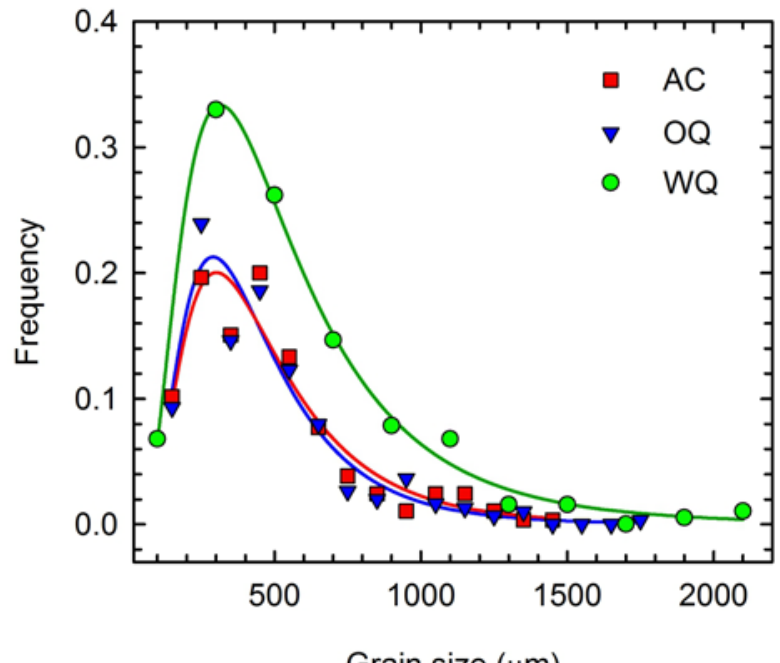

Fig. 13. Log-normal grain size distribution of the AC, OQ and WQ samples after the heat treatment route $\mathrm{C}$.

is the activation for grain growth, $R$ is the universal gas constant, and $T$ is the absolute temperature. As shown by Lapin and Klimová [48, 49] and Zhang et al. [50], the annealing in the $\alpha$ phase field leads to a fast growth of $\alpha$ grains which growth kinetics is characterised by the activation energy for grain growth of $Q=145 \mathrm{~kJ} \mathrm{~mol}^{-1}$ and time exponent of $n=0.36$. Since the annealing temperature of $1385^{\circ} \mathrm{C}$ is selected to be very close to $\alpha \rightarrow \alpha+\gamma$ transition temperature, the annealing time needs to be shortened to prevent undesirable grain growth and preserve smaller fully lamellar grains in the studied alloy. A grain size up to about $280 \mu \mathrm{m}$ has been suggested by Kim and Kim $[14,51]$ to maintain an optimal balance between the room and high-temperature mechanical properties of TiAl-based alloys.

It should be noted that the fast cooling rates occasionally lead to the formation of short cracks in the OQ and even long cracks in WQ samples [31]. Hence, such type of cooling could not be applied for the grain refinement of cast components in practice. Hence, air cooling leading to the formation of the only low volume fraction of the massive $\gamma_{\mathrm{M}}$ and fine lamellar microstructure combined with additional annealing in the $\alpha+\gamma$ or $\alpha$ phase fields can be considered to be a perspective method for the grain refinement of the studied peritectic alloy [52].

\section{Conclusions}

The effect of solid-state phase transformations on grain refinement of cast peritectic TiAl-based alloy has been studied. The following conclusions are reached:

1. The initial microstructure of as-cast samples 
consists of coarse fully lamellar $\alpha_{2}+\gamma$ grains characterised by a median grain size of $1310 \mu \mathrm{m}$. The boride $(\mathrm{Ti}, \mathrm{Nb}) \mathrm{B}$ particles are found to be ineffective to refine the microstructure of the alloy during solidification and solid-state phase transformations.

2. The pretreatment of the samples consisting of solution annealing in the $\alpha$ phase field followed by fast cooling leads to the formation of massive $\gamma_{\mathrm{M}}$ and fine lamellar microstructure. The volume fraction of the massive $\gamma_{\mathrm{M}}$ depends on the cooling medium and increases from 7 to 48 vol.\% by increasing the cooling rate from 15 to $48^{\circ} \mathrm{C} \mathrm{s}^{-1}$.

3 . The heat treatment route $\mathrm{A}$ composed of the pretreatment and subsequent annealing of the samples in the $\alpha+\gamma$ phase field leads to the formation of refined grain structure consisting of single $\gamma$ and convoluted $\alpha_{2}+\gamma$ grains characterised by a grain size ranging from 14 to $22 \mu \mathrm{m}$. The grain boundaries are found to be covered by coarsened $\alpha_{2}$ phase.

4. The heat treatment route $B$ composed of the heat treatment route $\mathrm{A}$ and subsequent annealing in the $\alpha+\gamma$ phase field leads to the formation of a refined duplex type of microstructure consisting of single $\gamma$ and lamellar $\alpha_{2}+\gamma$ grains characterised by a grain size ranging from 16 to $18 \mu \mathrm{m}$. The grain boundaries are found to be covered by coarsened $\alpha_{2}$ phase.

5 . The heat treatment route $\mathrm{C}$ composed of the heat treatment route $\mathrm{A}$ and subsequent annealing in the single $\alpha$ phase field leads to the formation of coarse grains with fully lamellar $\alpha_{2}+\gamma$ microstructure and grain size ranging from 395 to $472 \mu \mathrm{m}$.

\section{Acknowledgements}

This work was financially supported by the Slovak Research and Development Agency under the contract APVV-15-0660 and the Slovak Grant Agency for Science under the contract VEGA 2/0125/16. The experimental work was carried out thanks to the infrastructure supported by the Research and Development Operational Program funded by the European Regional Development Fund in the frame of the project "Long-term operation of nuclear power plants VVER 440 taking into account the environmental impact" (ITMS 26220220146).

\section{References}

[1] Haun, R. E.: JOM, 69, 2017, p. 2615. doi:10.1007/s11837-017-2578-1

[2] Bewlay, B. P., Nag, S., Suzuki, A., Weimer, M. J.: Mater. High Temp., 33, 2016, p. 549. doi:10.1080/09603409.2016.1183068

[3] Tetsui, T., Ono, S.: Intermetallics, 7, 1999, p. 689. doi:10.1016/S0966-9795(98)00085-5

[4] Wu, X.: Intermetallics, 14, 2006, p. 1114. doi:10.1016/j.intermet.2005.10.019
[5] Bünck, M., Stoyanov, T., Schievenbusch, J., Michels, H., Gußfeld, A.: JOM, 69, 2017, p. 2565. doi:10.1007/s11837-017-2534-0

[6] Liang, Y., Lin, J.: JOM, 69, 2017, p. 2571. doi:10.1007/s11837-017-2551-z

[7] Kim, Y.-W.: Intermetallics, 6, 1998, p. 623. doi:10.1016/S0966-9795(98)00037-5

[8] Appel, F., Wagner, R.: Mater. Sci. Eng. R, 22, 1998 , p. 187. doi:10.1016/S0927-796X(97)00018-1

[9] Dimiduk, D. M., Martin, P. L., Kim, Y. W.: Mater. Sci. Eng. A, 243, 1998, p. 66. doi:10.1016/S0921-5093(97)00780-6

[10] Lapin, J., Gabalcova, Z., Bajana, O., Pelachova, T., Stanekova, H., Frkanova, K.: In: Proceedings of the Gamma Titan. Alum. Alloy. Eds.: Kim, Y.-W., Wilfried, S., Lin, J., Dimiduk, D., Appel, F.: TMS (The Minerals, Metals \& Materials Society), 2014, p. 179. doi:10.1002/9781118998489.ch25

[11] Dimiduk, D. M., Hazzledine, P. M., Parthasarathy, T. A., Seshagiri, S., Mendiratta, M. G.: Metall. Mater. Trans. A Phys. Metall. Mater. Sci., 29, 1998, p. 37. doi:10.1007/s11661-998-0157-3

[12] Parthasarathy, T., Mendiratta, M., Dimiduk, D. M.: Scr. Mater., 37, 1997, p. 315. doi:10.1016/S1359-6462(97)00099-7

[13] Maruyama, K., Yamamoto, R., Nakakuki, H., Fujitsuna, N.: Mater. Sci. Eng. A, 239-240, 1997, p. 419. doi:10.1016/S0921-5093(97)00612-6

[14] Kim, Y. W., Kim, S. L.: Intermetallics, 53, 2014, p. 92. doi:10.1016/j.intermet.2014.04.006

[15] Srivastava, D., Hu, D., Chang, I. T. H., Loretto, M. H.: Intermetallics, 7, 1999, p. 1107. doi:10.1016/S0966-9795(99)00029-1

[16] Hu, D., Botten, R. R.: Intermetallics, 10, 2002, p. 701. doi:10.1016/S0966-9795(02)00047-X

[17] Huang, A., Hu, D., Loretto, M. H., Wu, X.: Intermetallics, 17, 2009, p. 285 doi:10.1016/j.intermet.2008.09.012

[18] Huang, A., Hu, D., Wu, X., Loretto, M. H.: Intermetallics, 15, 2007, p. 1147 . doi:10.1016/j.intermet.2007.02.002

[19] Hu, D., Huang, A. J., Wu, X.: Intermetallics, 15, 2007, p. 327. doi:10.1016/j.intermet.2006.07.007

[20] Hu, D.: Intermetallics, 9, 2001, p. 1037. doi:10.1016/S0966-9795(01)00079-6

[21] Wu, X., Hu, D.: Scr. Mater., 52, 2005, p. 731. doi:10.1016/j.scriptamat.2004.12.021

[22] Lapin, J., Gabalcová, Z., Bajana, O., Daloz, D.: Kovove Mater., 44, 2006, p. 297.

[23] Clemens, H., Bartels, A., Bystrzanowski, S., Chladil, H., Leitner, H., Dehm, G., Gerling, R., Schimansky, F. P.: Intermetallics, 14, 2006, p. 1380. doi:10.1016/i.intermet.2005.11.015

[24] $\mathrm{Hu}, \mathrm{D} ., \mathrm{Wu}, \mathrm{X} .$, Loretto, M. H.: Intermetallics, 13, 2005, p. 914. doi:10.1016/j.intermet.2004.12.002

[25] Sankaran, A., Bouzy, E., Humbert, M., Hazotte, A.: Acta Mater., 57, 2009, p. 1230. doi:10.1016/j.actamat.2008.11.012

[26] Dey, S. R., Bouzy, E., Hazotte, A.: Scr. Mater., 57, 2007, p. 365. doi:10.1016/j.scriptamat.2007.04.015

[27] Jiang, H., Zhang, K., Hao, X. J., Saage, H., Wain, N., Hu, D., Loretto, M. H., Wu, X.: Intermetallics, 18, 2010, p. 938. doi:10.1016/j.intermet.2010.01.006 
[28] Saage, H., Huang, A. J., Hu, D., Loretto, M. H., Wu, X.: Intermetallics, 17,2009 , p. 32 . doi:10.1016/j.intermet.2008.09.006

[29] Lapin, J., Pelachová, T., Dománková, M.: Intermetallics, 19, 2011, p. 814 .

doi:10.1016/j.intermet.2010.11.023

[30] Lapin, J., Pelachová, T., Witusiewicz, V. T. T., Dobročka, E.: Intermetallics, 19, 2011, p. 121. doi:10.1016/i.intermet.2010.09.016

[31] Lapin, J., Marek, K.: J. Alloys Compd., 735, 2018, p. 338. doi:10.1016/i.jallcom.2017.11.076

[32] Guyon, J., Hazotte, A., Bouzy, E.: J. Alloys Compd., 656, 2015, p. 667. doi:10.1016/j.jallcom.2015.09.179

[33] Hu, D., Yang, C., Huang, A., Dixon, M., Hecht, U.: Intermetallics, 22, 2012, p. 68. doi:10.1016/i.intermet.2011.11.003

[34] Hu, D.: Rare Met., 35, 2016, p. 1. doi:10.1007/s12598-015-0615-1

[35] Kamyshnykova, K., Lapin, J.: Vacuum, 154, 2018, p. 218. doi:10.1016/i.vacuum.2018.05.017

[36] Lin, J. P., Zhao, L. L., Li, G. Y., Zhang, L. Q., Song, X. P., Ye, F., Chen, G. L.: Intermetallics, 19, 2011, p. 131. doi:10.1016/j.intermet.2010.08.029

[37] Hecht, U., Witusiewicz, V., Drevermann, A., Zollinger, J.: Intermetallics, 16, 2008, p. 969. doi:10.1016/j.intermet.2008.04.019

[38] Li, M., Xiao, S., Xiao, L., Xu, L., Tian, J., Chen, Y.: J. Alloys Compd., 728, 2017, p. 206. doi:10.1016/j.jallcom.2017.08.211

[39] Schwaighofer, E., Rashkova, B., Clemens, H., Stark, A., Mayer, S.: Intermetallics, 46, 2014, p. 173. doi:10.1016/i.intermet.2013.11.011
[40] Cheng, T. T.: Intermetallics, 8, 2000, p. 29. doi:10.1016/S0966-9795(99)00063-1

[41] Kartavykh, A. V., Gorshenkov, M. V., Tcherdyntsev, V. V., Podgorny, D. A.: J. Alloys Compd., 586, 2014, p. S153. doi:10.1016/j.jallcom.2013.03.104

[42] Veeraraghavan, D., Wang, P., Vasudevan, V. K.: Acta Mater., 51, 2003, p. 1721. doi:10.1016/S1359-6454(02)00572-4

[43] Dey, S. R., Bouzy, E., Hazotte, A.: Intermetallics, 14, 2006, p. 444.

[44] Denquin, A., Naka, S.: Acta Mater., 44, 1996, p. 353. doi:10.1016/1359-6454(95)00168-6

[45] Yang, J., Wang, J. N., Wang, Y., Xia, Q.: Intermetallics, 11, 2003, p. 971. doi:10.1016/S0966-9795(02)00126-7

[46] Thomas, M., Bacos, M.-P.: Aerosp. Lab, 3, 2011, p. 1.

[47] Denquin, A., Naka, S.: Acta Mater., 44, 1996, p. 343. doi:10.1016/1359-6454(95)00167-4

[48] Lapin, J., Klimová, A.: J. Mater. Sci. Lett., 22, 2003, p. 1275. doi:10.1023/A:1025462220021

[49] Lapin, J., Klimová, A.: Kovove. Mater., 41, 2003, p. 1.

[50] Zhang, W. J., Evangelista, E., Francesconi, L.: Mater. Sci. Eng. A, 220, 1996, p. 15. doi:10.1016/S0921-5093(96)10435-4

[51] Kim, Y.-W., Kim, S.-L.: JOM, 70, 2018, p. 553. doi:10.1007/s11837-018-2747-x

[52] Lapin, J., Kamyshnykova, K.: Intermetallics, 98, 2018, p. 34. doi:10.1016/j.intermet.2018.04.012 